\title{
ATIVIDADE ANTIMICROBIANA DE DIVERSOS ÓLEOS ESSENCIAIS EM MICRORGANISMOS ISOLADOS DO MEIO AMBIENTE
}

\author{
FERNANDA MARIA PAGANE GUERESCHI ERNANDES * \\ CRISPIN HUMBERTO GARCIA-CRUZ **
}

\begin{abstract}
Determinou-se a atividade antimicrobiana de oito óleos essenciais extraídos por arraste de vapor sob pressão reduzida (alho, canela, cebola, cravo do Brasil, cravo da Índia, gengibre, hortelã e orégano) e outros dois (hortelã e menta) adquiridos no comércio varejista sobre 26 microrganismos isolados do meio ambiente. Utilizaram-se inóculos padronizados, previamente desenvolvidos em caldo nutriente e semeados em superfície de Plate Count Agar (PCA), distribuídos em placas de Petri. Foram utilizados antibióticos das séries Gram positivas e Gram negativas como padrão de referência da suscetibilidade dos microrganismos. As diluições dos óleos essenciais foram impregnadas em disco de papel e esses depositados sobre a superfície de ágar previamente semeada. Após incubação por $72 \mathrm{~h}$ a $30^{\circ} \mathrm{C}$, com observação a cada $24 \mathrm{~h}$, os resultados obtidos (halo de inibição ao redor do disco de papel) mostraram que o óleo essencial de cravo do Brasil afetou maior número de microrganismos, seguido pelos óleos de cravo da Índia e hortelã. Dos microrganismos testados, as leveduras foram as mais resistentes e as bactérias Gram positivas mais sensíveis aos óleos essenciais quando comparadas com as Gram negativas. Os óleos concentrados apresentaram maior efeito que as respectivas diluições. A concentração a 10\% foi a mais eficiente, sendo observado que maior concentração do óleo essencial aumenta o efeito inibitório. Alguns dos óleos essenciais apresentaram melhor desempenho do que os antibióticos utilizados como padrão.
\end{abstract}

PALAVRAS-CHAVE: ATIVIDADE ANTIMICROBIANA; ÓLEOS ESSENCIAIS.

* Farmacêutica, doutoranda do Programa de Pós-graduação em Engenharia e Ciência de Alimentos, Departamento de Engenharia e Tecnologia de Alimentos, Instituto de Biociências, Letras e Ciências Exatas, Universidade Estadual Paulista (UNESP), São José do Rio Preto, SP (e-mail: fernandaer@ig.com.br).

** Químico Farmacêutico Industrial, docente do curso de Engenharia de Alimentos e do Programa de Pósgraduação em Engenharia e Ciência de Alimentos, Departamento de Engenharia e Tecnologia de Alimentos, Instituto de Biociências, Letras e Ciências Exatas, UNESP, São José do Rio Preto, SP (email: crispin@ibilce.unesp.br). 


\section{INTRODUÇÃO}

A indústria alimentícia visa a produção de alimentos que apresentem vida-de-prateleira longa e inocuidade com relação à presença de microrganismos patógenos e suas toxinas. Porém, a nova tendência do consumidor e da legislação de alimentos têm tornado essa busca cada vez mais premente e necessária. Os consumidores procuram alimentos de boa qualidade (frescos, com pouca quantidade de sal, açúcar, gordura e ácidos, entre outros), livres de preservativos e minimamente processados, porém com vida-útil longa (GOULD, 1995).

A conservação química limita a utilização do rótulo "alimento natural", embora seja fundamental na questão da segurança (BEDIN, GUTKOSKI e WIEST, 1999). A legislação tem restringido e/ou limitado o emprego de alguns conservantes comumente utilizados em diferentes alimentos. Isto tem criado problemas para a indústria, pois alguns microrganismos apresentam resistência aos agentes preservantes utilizados de forma rotineira (PIPER et al., 1998).

Com a difusão das modernas técnicas de preservação houve interesse acentuado e renovado sobre algumas especiarias, utilizadas principalmente como condimentos alimentares. Além de participarem como ingredientes de inúmeros alimentos, tornando-os mais saborosos e digestivos, apresentam ação indireta e complementar como agentes antimicrobianos devido à presença de óleos essenciais. Esses são constituídos por princípios ativos voláteis que podem ser obtidos mediante métodos de extração (WIEST, 1999). Suas concentrações nos alimentos são determinadas pela preferência de sabores e, normalmente, encontram-se entre 0,5 a 1,0\% no produto final. As substâncias químicas dos óleos essenciais apresentam compostos capazes de inibir direta ou indiretamente os sistemas enzimáticos bacterianos, mesmo que a maioria de microrganismos seja ainda desconhecida. Seu comportamento é semelhante ao dos antibióticos, que são definidos como "substâncias químicas com capacidade para matar ou inibir o desenvolvimento de bactérias ou outros microrganismos". A caracterização da célula "alvo" é decisiva para essa aplicação e somente os compostos naturais, que agem sobre sistemas essenciais para a reprodução e sobrevivência desses microrganismos, têm atividade antibiótica. Assim a inativação desses sistemas no metabolismo celular tem efeitos letais (KURYLOWICZ, 1981).

Grande número de pesquisas citam as propriedades antibacterianas e antifúngicas das especiarias in natura, seus óleos essenciais e seus extratos. Várias plantas usadas para aromatizar alimentos são apontadas por apresentarem atividade antimicrobiana como, por exemplo, louro, manjerona, manjericão, cravo, canela, coentro, melissa, limão, laranja, alecrim, menta, alho, entre outras (BEUCHAT e GOLDEN, 1989). O primeiro relatório sobre propriedades antimicrobianas, publicado em 1880 , descreve a atividade antimicrobiana de óleos essenciais de mostarda, cravo da índia e canela (BOYLE, 1995). Extratos de alho, canela, curry, mostarda, manjericão, gengibre a outras ervas exibem também propriedades antimicrobianas (ARORA, e KAUR, 1999; MARINO, BERSANI e COMI, 1999). Extratos do cravo da Índia reduzem o número de Escherichia coli e outras bactérias durante a armazenagem de sucos, leites e chás (MAU, CHEN e HSIEH, 2001).

BEUCHAT e GOLDEN (1989) citam várias plantas com atividade antimicrobiana e destacaram que, em alguns casos, os óleos essenciais potencializam outros agentes antimicrobianos. Desta forma, é necessário estudar novos agentes que possam auxiliar a substituição racional dos conservantes químicos comumente utilizados no controle microbiano e possibilitar sua inserção nos sistemas de conservação de alimentos.

As especiarias e seus derivados assumiram relevante importância para serem usados como potenciais agentes inibitórios de microrganismos. Esses elementos que se destacavam, principalmente, como agentes para conferir aromas e gostos característicos aos alimentos revelaram nova perspectiva para seu emprego na indústria de alimentos. 
O objetivo deste trabalho foi avaliar o efeito antimicrobiano de óleos essenciais extraídos de especiarias, utilizados na culinária brasileira, e de outros óleos essenciais sobre vinte e seis microrganismos isolados do meio ambiente. Pretendeu-se também comparar a suscetibilidade desses microrganismos frente a antibióticos das séries Gram positivas e Gram negativas.

\section{MATERIAL E MÉTODOS}

\subsection{OBTENÇÃO DOS MICRORGANISMOS}

Foram utilizados vinte e seis microrganismos isolados do meio ambiente, desenvolvidos a $30^{\circ} \mathrm{C}$ por 24 horas em caldo nutriente antes de cada análise, sendo nove bactérias Gram negativas (13D; 17F; 18F; 19F; 24A; 35A; 36A; 37A e 39A), dez Gram positivas (1C; 1D; 1F; 3F; 4F; 5E; 11D; $17 \mathrm{E} ; 19 \mathrm{E}$ e 22F) e sete leveduras (A, D, E, 13A; 13B; 14A e 14B). Todos os microrganismos pertencem a coleção de culturas do Departamento de Engenharia e Tecnologia de Alimentos, laboratório de Microbiologia de Alimentos da Universidade Estadual Paulista (UNESP), São José do Rio Preto, SP.

\subsection{OBTENÇÃO DOS ÓLEOS ESSENCIAIS}

Oito óleos essenciais foram extraídos pelo método de arraste de vapor sob pressão reduzida, conforme proposto por GONÇALVEZ (1990), a partir de amostras in natura de alho, cebola, canela, cravo do Brasil, cravo da Índia, gengibre, hortelã e orégano. Duas amostras de óleos essenciais (menta e hortelã) foram obtidas no comércio da cidade de São José do Rio Preto, SP, Brasil.

\subsection{ENSAIO DA RESISTÊNCIAAOS ÓLEOS ESSENCIAIS}

Utilizaram-se inóculos padronizados dos vinte e seis microrganismos, previamente cultivados a $30^{\circ} \mathrm{C}$ por 24 horas em caldo nutriente. Esses foram inoculados, em duplicata, pela técnica de plaqueamento em superfície de Plate Count Agar (PCA), distribuído em placas de Petri. Em cada placa foi colocado um disco de papel filtro estéril com $65 \mathrm{~mm}$ de diâmetro, previamente imergido por 24h em frascos âmbar, contendo os óleos essenciais a 10,0; 1,0 e 0,1\% (v/v) em água destilada. Todas as placas semeadas foram incubadas a $30^{\circ} \mathrm{C}$ por até $72 \mathrm{~h}$ com observação diária para verificar a presença de halos de inibição em torno do disco de papel e confirmar ou não a resistência dos microrganismos frente aos óleos testados. O tamanho do halo de inibição serviu como parâmetro para indicar a maior ou menor suscetibilidade dos microrganismos aos óleos essenciais (HOFFMANN et al., 1999).

\section{RESULTADOS E DISCUSSÃO}

Os princípios ativos dos condimentos estão inseridos na classe dos conservantes de ocorrência natural nos alimentos. A intensidade da ação inibitória desses compostos depende da natureza da matéria-prima e do método de extração para a obtenção dos óleos essenciais, do tipo de microrganismo a ser controlado e de fatores relacionados ao armazenamento de alimentos como, temperatura, umidade e conservantes químicos utilizados (KUNZ e GROHS, 2000). 
O teste do antibiograma apresentou resultados reprodutíveis durante a verificação da resistência ou suscetibilidade dos microrganismos frente aos óleos essenciais. Foram utilizadas bactérias Gram negativas, Gram positivas e leveduras, bem como dez tipos de óleos essenciais concentrados e diluídos (10,0, 1,0 e 0,1\%), perfazendo quatro testes por microrganismo. Os nomes comuns e científicos, família e parte das plantas utilizadas para extração dos óleos essenciais estão descritos na Tabela 1.

\section{TABELA 1 - PLANTAS E PARTE DAS PLANTAS USADAS PARA EXTRAÇÃO DO ÓLEO ESSENCIAL PELO MÉTODO DE ARRASTE DE VAPOR SOB PRESSÃO REDUZIDA}

\begin{tabular}{c|c|c|c}
\hline Nome comum & Nome científico & Família & Parte da planta \\
\hline Alho & Allium sativum & Liliáceas & Bulbo \\
Canela & Cinnamomum zeylanicuym & Lauráceas & Casca \\
Cebola & Allium cepa & Liliáceas & Bulbo \\
Cravo do Brasil & Dianthus caryophyllus & Cariofiláceas & Flor \\
Cravo da Îndia & Eugenia cariophyllata & Mirtáceas & Flor \\
Gengibre & Zingiber officinale & Zingiberáceas & Raiz \\
Hortelã verde & Mentha viridis & Labiadas & Folha \\
Menta & Mentha arvensis & Labiadas & Folha \\
Óregano & Origanum vulgare & Labiadas & Folha \\
\hline
\end{tabular}

As Tabelas 2 e 3 correspondem à ação dos óleos essenciais testados sobre os três grupos de microrganismos isolados do meio ambiente (leveduras, bactérias Gram positivas e Gram negativas).

ARORA e KAUR (1999) relataram que o tamanho do halo de inibição indica a maior ou menor suscetibilidade dos microrganismos frente as substâncias inibidoras. Classificaram os halos de inibição com base no tamanho do diâmetro (incluindo o diâmetro do disco de papel filtro), sendo os valores menores que $7 \mathrm{~mm}$ considerados não-ativos contra os microrganismos testados. Os halos de inibição de $12 \mathrm{~mm}$ de diâmetro ou maiores foram considerados como os de melhor efeito inibitório provocado pelo óleo essencial testado.

Verificou-se (Tabelas 2 e 3) maior porcentagem de halos de inibição formados com o óleo essencial de cravo do Brasil $(45,2 \%)$, seguido pelo de cravo da Índia (43,3\%), hortelã (comprado) $(42,3 \%)$, canela $(41,0 \%)$, gengibre $(38,5 \%)$, hortelã $(37,5 \%)$, menta $(32,7 \%)$, alho $(30,8 \%)$, cebola $(29,8 \%)$ e orégano $(25,0 \%)$. As leveduras mostraram-se as mais resistentes com apenas $26,1 \%$ de halos de inibição formados. As bactérias Gram positivas foram mais sensíveis aos óleos essenciais com $44,2 \%$ de freqüência de halos formados em relação às Gram negativas $(36,7 \%)$.

O óleo essencial de hortelã (comprado) evidenciou maior eficácia contra leveduras e bactérias Gram negativas, enquanto que o de cravo do Brasil e cravo da Índia mostraram-se mais eficazes contra as Gram positivas. Resultados semelhantes em relação ao cravo foram citados por outros pesquisadores. BRIOZZO et al. (1989) analisaram a atividade do óleo essencial de cravo e verificaram que a concentração de $0,4 \%$ foi suficiente para eliminar $99,99 \%$ de microrganismos como, Cândida albicans, Pseudomonas aeruginosa, cinco linhagens de Staphylococcus aureus, Escherichia coli, Klebsiella pneumoniae e Clostridium perfringens. DEANS e KITCHIE (1987) examinaram quatro concentrações de óleos essenciais (não-diluída e diluída a 1:2; 1:5; 1:10 em etanol absoluto) sobre vinte e cinco gêneros de bactérias, relatando que a canela e o cravo enquadraram-se entre os extratos mais eficazes. 


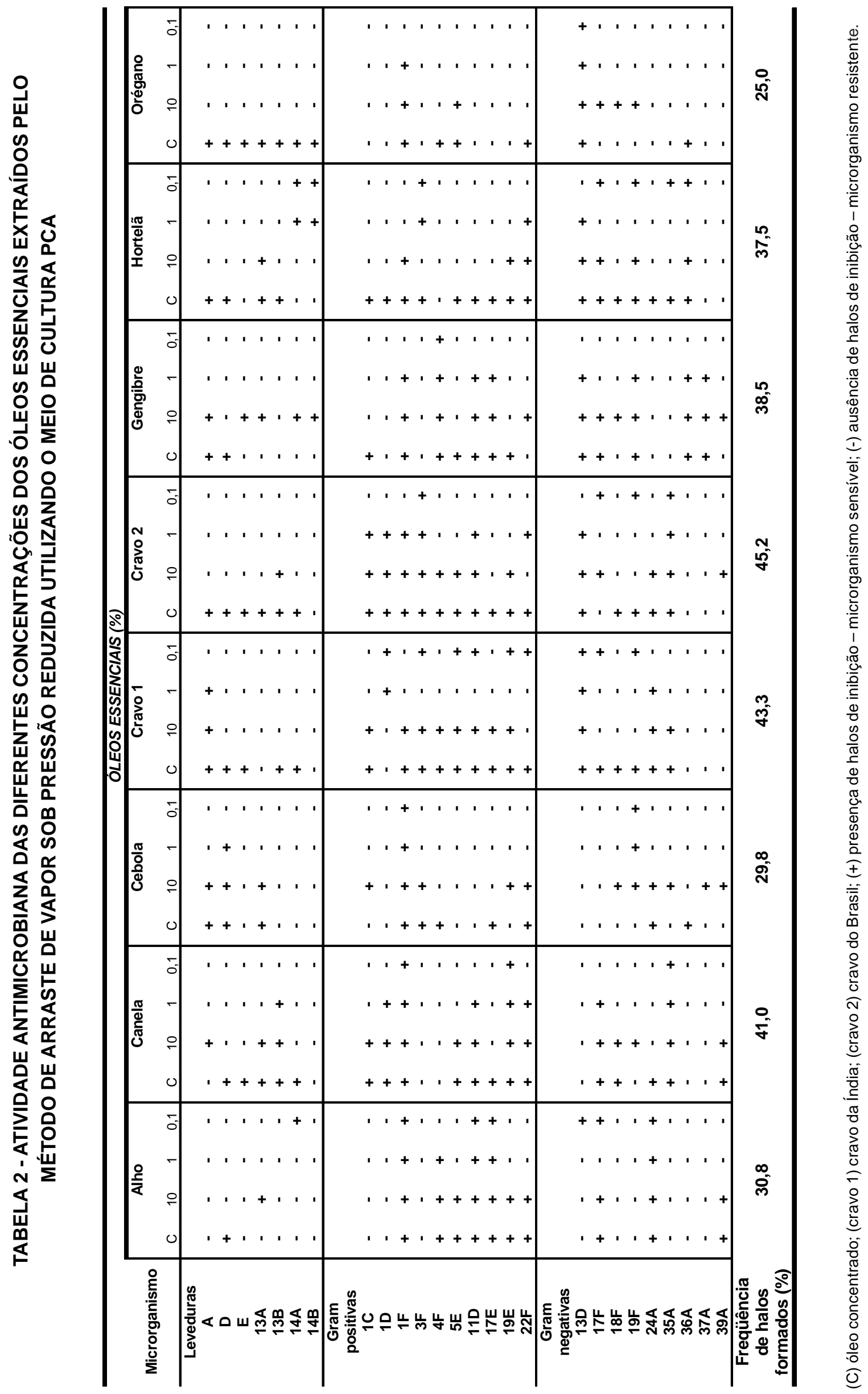


Dentre os derivados de plantas consumidas na dieta humana, o Allium spp, $A$. sativum (alho), A. cepa (cebola) e A. porrum (alho porro) provavelmente são as mais reconhecidas e estudadas quanto a sua atividade antimicrobiana (BEDIN, GUTKOSKI e WIEST, 1999). Apesar do óleo essencial de alho não ter sido enquadrado entre os melhores agentes antimicrobianos nesta pesquisa, vários autores relatam sua boa ação inibitória. KYUNG, PARK e KIM (1996) relataram que $1-2 \%$ do extrato de alho ( $A$. sativum) inibe o desenvolvimento bacteriano e que em altas concentrações esse extrato apresenta ação bactericida. ISMAIEL e PIERSON (1988) testaram o efeito dos óleos essenciais de cravo, tomilho, pimenta preta, pimenta, orégano, alho, cebola e canela na germinação, desenvolvimento pós-germinação e produção de toxina de Clostridium botulinum (seis linhagens dos tipos A, B e E) em meio de cultura microbiológico. O óleo de alho foi o mais potente inibidor da germinação. Os óleos de pimenta preta, cravo, canela e orégano foram os mais fortes inibidores do desenvolvimento vegetativo.

\section{TABELA 3 - ATIVIDADE ANTIMICROBIANA DAS DIFERENTES CONCENTRAÇÕES DOS ÓLEOS ESSENCIAIS DE HORTELÃ E MENTA (ADQUIRIDOS NO COMÉRCIO) UTILIZANDO O MEIO DE CULTURA PCA}

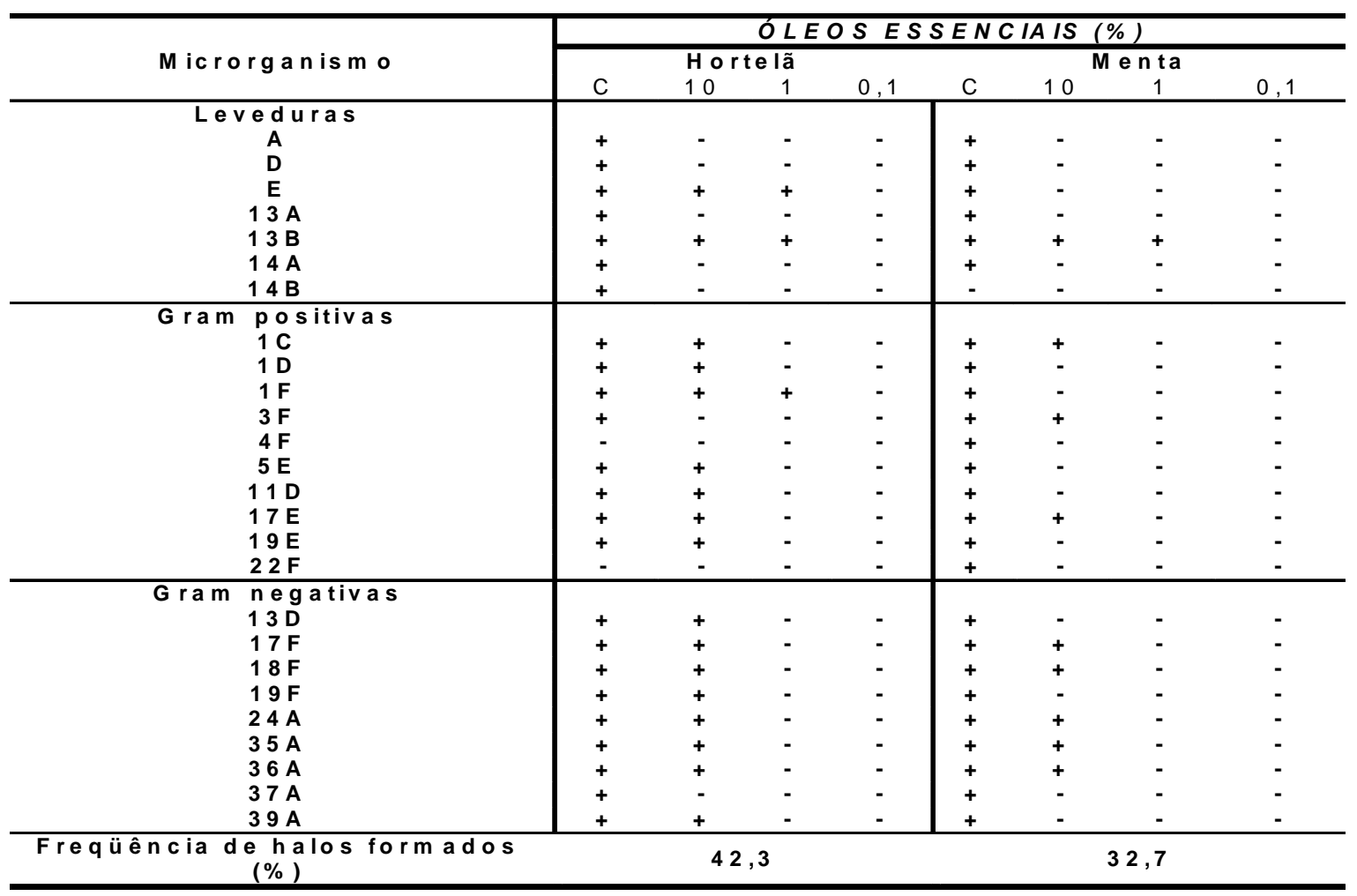

(C) óleo concentrado; (cravo 1) cravo da Índia; (cravo 2) cravo do Brasil; (+) presença de halos de inibição - microrganismo sensível; (-) ausência de halos de inibição - microrganismo resistente

O óleo essencial de orégano (Tabela 2) revelou a menor ação sobre os microrganismos testados, principalmente contra as bactérias Gram negativas e Gram positivas, porém o efeito desse óleo essencial sobre a Salmonella spp está bem documentado (NYCHAS, 1995). KOUTSOUMANIS, LAMBROPOULOU e NYCHAS (1999) testaram o efeito de diferentes concentrações do óleo essencial de orégano $(0,0 ; 0,5 ; 1,0$ e 2,0\% v/v) e verificaram declínio no número de células de Salmonella Enteritidis imediatamente após a inoculação. ISMAIEL e PIERSON (1990) revelaram o efeito antimicrobiano da combinação do óleo de orégano e $\mathrm{NaNO}_{3}$ no desenvolvimento e produção de toxina do Clostridium botulinum em sistemas modelo de carne. 
O óleo de canela também se mostrou eficaz, agindo principalmente sobre as bactérias Gram positivas (Tabela 2). Segundo BULLERMAN (1974); MOROZUMI (1978) e DWIVIDI e DUBEY (1993) são três os componentes da canela que têm sido identificados como agentes antibacterianos: aldeído cinâmico, o-metoxicinamaldeído e carfone. Alguns estudos destacaram o óleo de canela como agente inibidor de fungos toxinogênicos (SALMERAM e POZO, 1991; PATKAR et al., 1993) e a atividade dos três componentes contra Aspergillus flavus (MONTES-BELMONT e CARVAJAL, 1998).

A sensibilidade dos microrganismos aos óleos essenciais testados evidenciou comportamento diferente de acordo com o óleo essencial e a concentração testada. A levedura 14B foi a mais resistente, sendo que das 40 amostras analisadas dos óleos essenciais (concentrados e diluídos) $87,5 \%$ não apresentaram efeito inibitório. A melhor atividade antimicrobiana dos óleos essenciais foi observada contra a bactéria Gram positiva 1F, não havendo formação de halos de inibição em apenas $27,5 \%$ do total das amostras analisadas.

A sensibilidade dos diferentes grupos de microrganismos (leveduras, bactérias Gram negativas e Gram positivas) à atividade antimicrobiana dos óleos essenciais consta no Gráfico 1. A levedura 13B mostrou-se a mais sensível, com 32,5\% de incidência de halos de inibição formados, seguida pelas leveduras A, D e 13A, sendo a cepa 14B a mais resistente. O óleo essencial concentrado de hortelã (adquirido no comércio) conseguiu inibir todas as leveduras e o de alho mostrou a menor eficácia (Tabelas 2 e 3).

\section{GRÁFICO 1 - EFEITO INIBITÓRIO DOS ÓLEOS ESSENCIAIS CONCENTRADOS E NA DILUIÇÃO DE 10\% SOBRE A LEVEDURA MAIS SENSÍVEL (13B) E A MAIS RESISTENTE (14B)}

13B

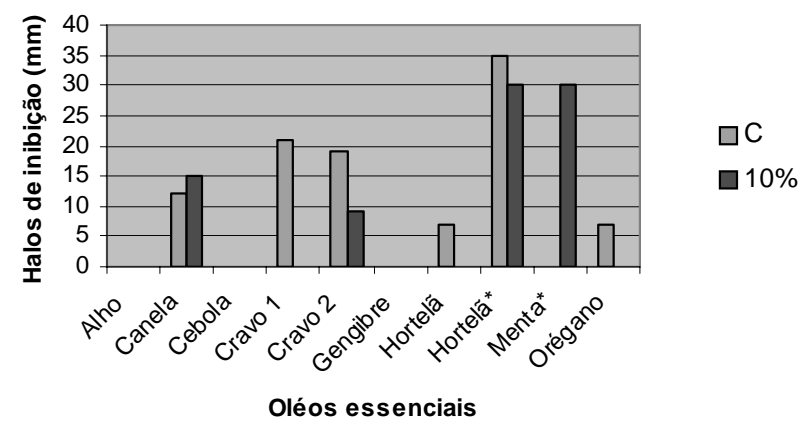

14B

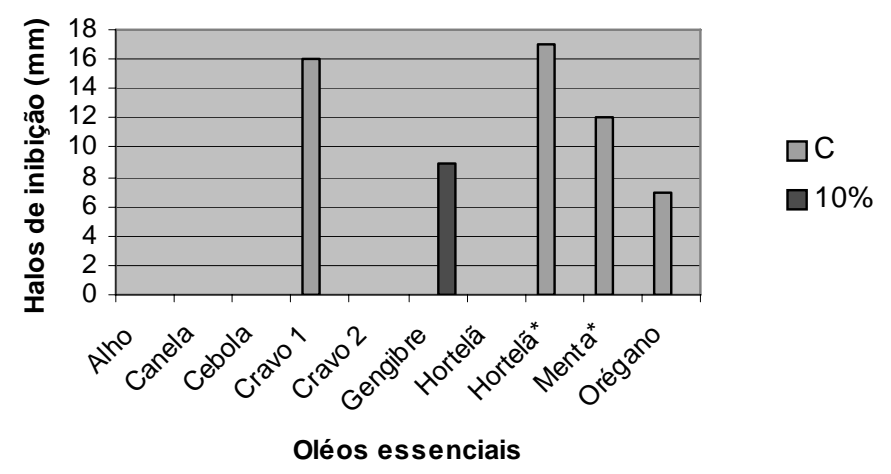

Cravo 1 (cravo da Índia); cravo 2 (cravo do Brasil); (*) óleos essenciais adquiridos no comércio. 
Em relação às bactérias Gram positivas, 1F (mais sensível) foi inibida por todos os óleos concentrados e na diluição de 10\%, excetuando-se o óleo de menta. As mais resistentes foram 1D e 4F, sendo que os óleos de cebola e orégano não exerceram efeito em nenhuma diluição testada (Gráfico 2). De acordo com a freqüência de halos de inibição formados, o óleo essencial de cravo do Brasil foi considerado o melhor (62,5\% de freqüência), seguido pelos de cravo da Índia (60,0\%) e canela (55,0\%). O restante dos óleos apresentou resultado inferior, principalmente o de orégano (com apenas $27,5 \%$ de freqüência de halos nas amostras analisadas).

Das bactérias Gram negativas, a 13D foi a mais sensível e a 37A a mais resistente. O óleo essencial de hortelã (adquirido no comércio) demonstrou maior poder inibitório sobre as bactérias e os de alho e cebola o menor (Gráfico 3).

\section{GRÁFICO 2 - EFEITO INIBITÓRIO DOS ÓLEOS ESSENCIAIS CONCENTRADOS E NA DILUIÇÃO DE 10\% SOBRE A BACTÉRIA GRAM POSITIVA MAIS SENSÍVEL (1F) E A MAIS RESISTENTE (17E)}

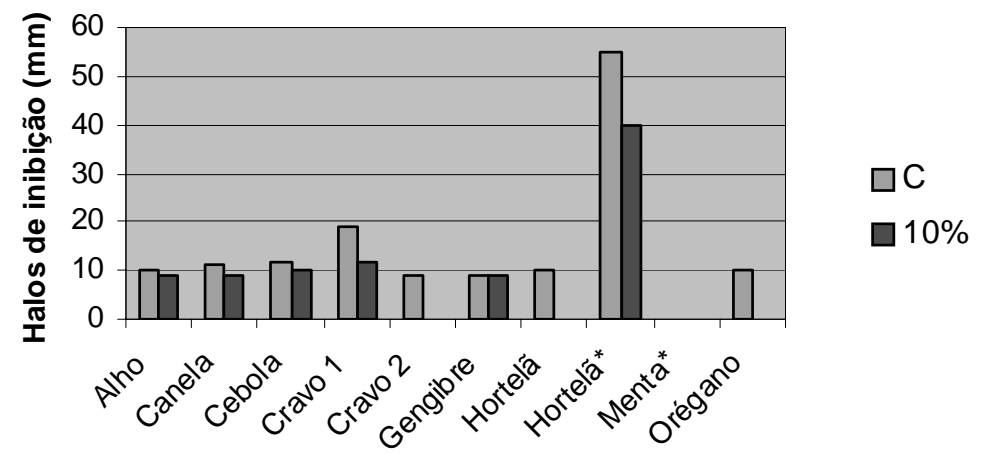

Óleos essenciais

17E

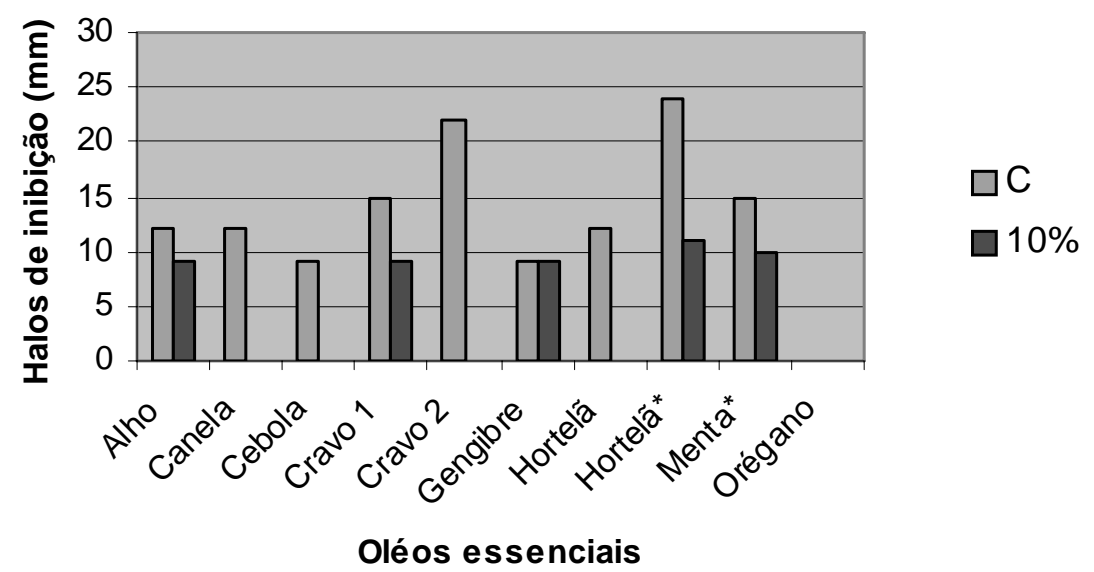

Cravo 1 (cravo da Índia); cravo 2 (cravo do Brasil); (*) óleos essenciais adquiridos no comércio. 


\section{GRÁFICO 3 - EFEITO INIBITÓRIO DOS ÓLEOS ESSENCIAIS CONCENTRADOS E NA DILUIÇÃO DE 10\% SOBRE A BACTÉRIA GRAM NEGATIVA MAIS SENSÍVEL (13D) E A MAIS RESISTENTE (37A)}

13D

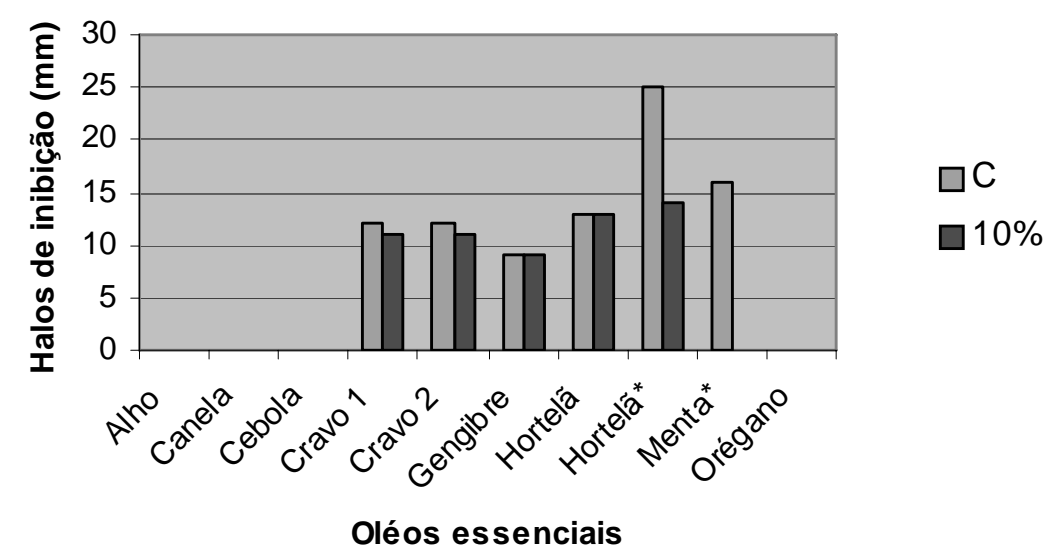

$37 \mathrm{~A}$

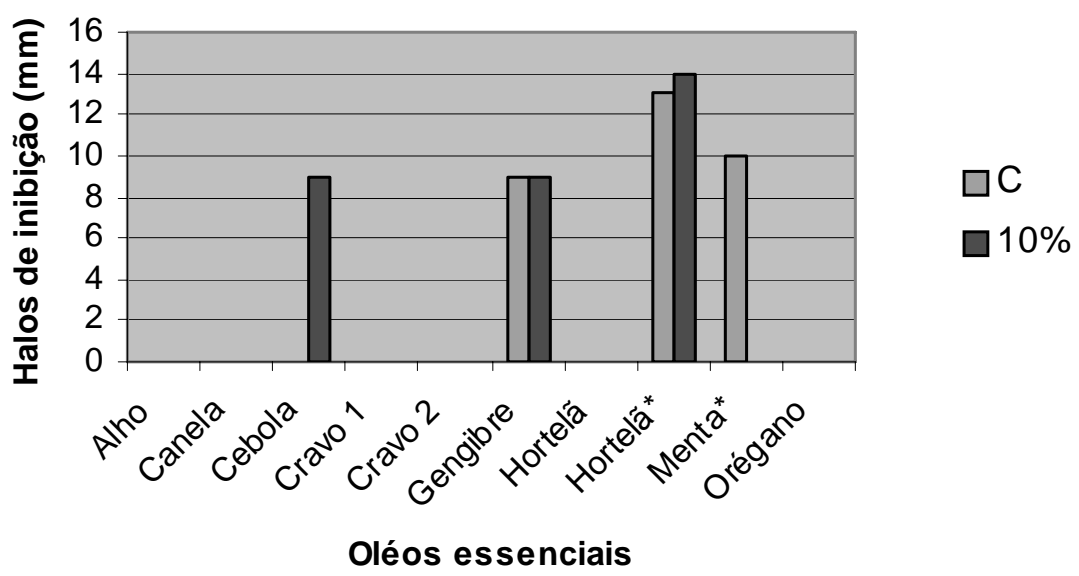

Cravo 1 (cravo da Índia); cravo 2 (cravo do Brasil); (*) óleos essenciais adquiridos no comércio.

A única entre as diluições testadas que causou halos de inibição superiores a $12 \mathrm{~mm}$ foi a 10\%, dependendo da bactéria e do óleo essencial. AURELI, CONSTANTINI e ZOLEA (1992) observaram a atividade de 32 óleos essenciais de especiarias, utilizadas na indústria de alimentos, sobre variantes de Listeria monocytogenes. Os óleos essenciais considerados mais potentes foram os de alho, canela, tomilho, orégano e pimenta que mostraram consistente e significativa zona de inibição de 34 a $45 \mathrm{~mm}$. Resultados semelhantes podem ser observados na Tabela 4 com o óleo essencial concentrado de hortelã (comprado), que formou halos de inibição de tamanhos significativos com os microrganismos testados.

Os óleos concentrados geralmente apresentaram maior efeito sobre as bactérias Gram negativas, porém resultados inferiores quando comparados com as bactérias Gram positivas e leveduras (Tabela 4). Os óleos essenciais concentrados de cravo do Brasil, cravo da Índia (família Compostas) e de hortelã (família Labiadas) apresentaram o maior efeito inibitório (halos superiores a $12 \mathrm{~mm}$ de diâmetro), sendo considerados os melhores agentes antimicrobianos. Esses resultados estão de acordo com COZENTINO et al. (1999) e ELGAYYAR et al. (2001) que estudaram os óleos essenciais de muitas 
plantas aromáticas pertencentes à família das Labiadas. Os óleos essenciais de manjericão, cravo da Índia, tomilho e alecrim tiveram seu poder antimicrobiano testado em Listeria monocytogenes e outros microrganismos patogênicos por SMITH-PALMER, STEWART e FYFE (1998) e O'GARA et al. (2000). MAU, CHEN e HSIEH (2001) observaram que extratos de cássia reduziram a contagem de células de Escherichia coli e outras bactérias durante a estocagem de sucos, leites e chás.

Os resultados do efeito de diversos antibióticos sobre alguns microrganismos estudados nesta pesquisa (Tabela 5) evidenciaram zonas de inibição com tamanhos semelhantes, como 0 óleo essencial de cravo do Brasil e o antibiótico amicacina contra a levedura 13B. Além disso, as bactérias Gram positivas reagiram com maior sensibilidade tanto com os óleos quanto com os antibióticos em relação às Gram negativas. O mesmo comportamento já tinha sido constatado por NAKATANI (1994). Outros pesquisadores observaram que a maior resistência das bactérias Gram negativas seria devido à presença de lipopolissacarídeos celulares que evitariam o transporte na membrana celular, bem como sua entrada à célula (KABARA, 1979; BRANEN, DAVIDSON e KATZ, 1980; FARAG, DAW e ABO-RAYA, 1989; RUSSEL, 1991; MCKELLAR et al., 1992).

Os óleos essenciais de cravo do Brasil, cravo da Índia e de hortelã (adquirido no comércio) demonstraram atividade sobre a bactéria 13D, resistente a ampicilina, cefalotina, sulfazotrim e tretraciclina. O óleo essencial de hortelã mostrou-se mais potente em relação aos outros agentes inibidores com halos de inibição de até $60 \mathrm{~mm}$, enquanto que o maior halo formado pelos antibióticos foi de $43 \mathrm{~mm}$ com cefalotina que inibiu a bactéria Gram positiva $5 \mathrm{E}$.

\section{TABELA 4 - COMPARAÇÃO ENTRE O TAMANHO DOS HALOS DE INIBIÇÃO FORMADOS NAS PLACAS DE PETRI CONTENDO LEVEDURAS, BACTÉRIAS GRAM POSITIVAS E GRAM NEGATIVAS NA PRESENÇA DOS ÓLEOS ESSENCIAIS CONCENTRADOS DE CRAVO DO BRASIL, CRAVO DA ÍNDIA E HORTELÃ USANDO PCA COMO MEIO DE CULTURA}

\begin{tabular}{|c|c|c|c|c|}
\hline \multirow{2}{*}{\multicolumn{2}{|c|}{ Microrganis mos }} & \multicolumn{3}{|c|}{ Halos de inibição $(m \mathrm{~m})$} \\
\hline & & Cravo do Brasil & Cravo da Índia & Hortelã \\
\hline \multicolumn{5}{|c|}{ Leveduras } \\
\hline & A & 26 & 31 & 14 \\
\hline & $\mathrm{D}$ & 31 & 40 & 26 \\
\hline & $\mathrm{E}$ & - & 29 & 50 \\
\hline & $13 \mathrm{~A}$ & 23 & - & 12 \\
\hline & $13 \mathrm{~B}$ & 19 & 21 & 50 \\
\hline & $14 \mathrm{~A}$ & 18 & 14 & 13 \\
\hline & $14 B$ & - & 16 & 17 \\
\hline \multicolumn{5}{|c|}{ Gram positivas } \\
\hline & $1 \mathrm{C}$ & 20 & 20 & 61 \\
\hline & $1 \mathrm{D}$ & - & - & 22 \\
\hline & $1 \mathrm{~F}$ & - & 19 & 55 \\
\hline & $3 \mathrm{~F}$ & 15 & 20 & 12 \\
\hline & $4 \mathrm{~F}$ & - & 16 & - \\
\hline & $5 \mathrm{E}$ & - & 20 & 22 \\
\hline & $11 \mathrm{D}$ & - & - & 25 \\
\hline & $17 \mathrm{E}$ & 22 & 15 & 24 \\
\hline & $19 \mathrm{E}$ & 12 & 20 & 18 \\
\hline & $22 \mathrm{~F}$ & - & - & - \\
\hline \multicolumn{5}{|c|}{ Gram negativas } \\
\hline & $13 \mathrm{D}$ & 12 & 12 & 25 \\
\hline & $17 \mathrm{~F}$ & - & 15 & 13 \\
\hline & $18 \mathrm{~F}$ & - & - & 15 \\
\hline & $19 \mathrm{~F}$ & 17 & 20 & 22 \\
\hline & $24 \mathrm{~A}$ & 31 & 28 & 20 \\
\hline & $35 \mathrm{~A}$ & - & - & 24 \\
\hline & $36 \mathrm{~A}$ & - & - & 33 \\
\hline & $37 \mathrm{~A}$ & - & - & 13 \\
\hline & $39 \mathrm{~A}$ & - & - & 25 \\
\hline
\end{tabular}




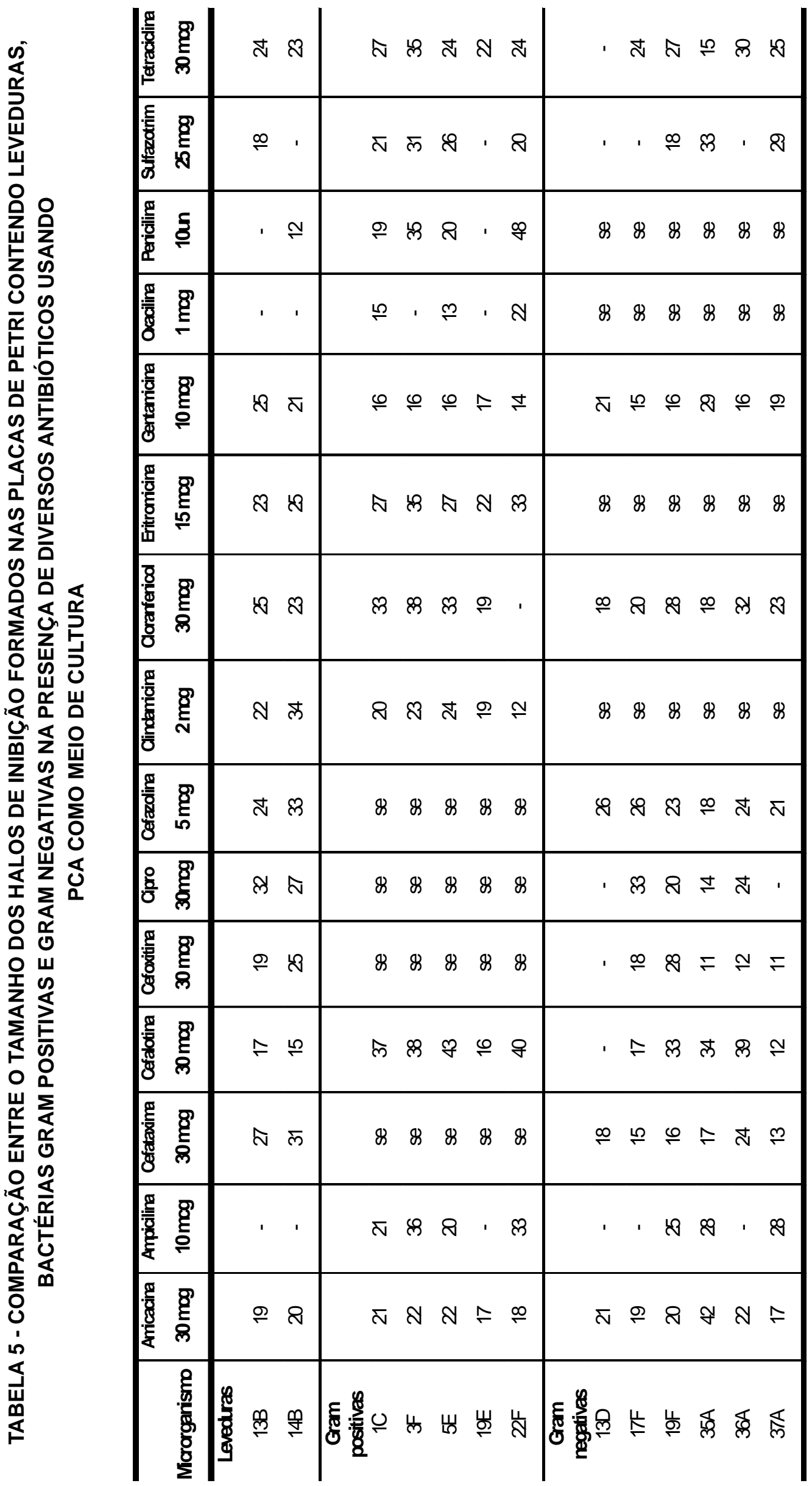




\section{CONCLUSÃO}

Os resultados da atividade antimicrobiana dos óleos essenciais sobre diferentes microrganismos mostraram que esses representam alternativa natural para compor sistemas de conservação de alimentos, podendo ser usados como substitutos de conservantes químicos. Entretanto, devem ser conduzidas pesquisas em nível de planta piloto para analisar suas aplicações comerciais.

\section{ABSTRACT}

\section{ANTIMICROBIAL ACTIVITY OF VARIOUS ESSENTIAL OILS ON MICROORGANISMS ISOLATED FROM THE ENVIRONMENT}

It was determined the antimicrobial activity of eight essential oils extracted by Carry of Steam under Reduced Pressure (garlic, cinnamon, onion, Brazilian clove, Indian clove, ginger, peppermint and oregano) and two others (peppermint and mint) bought at the retail trade on 26 microorganisms isolated from the environment. Standardized inocula, previously grown in nutrient broth and surface plated on Petri dishes containing PCA were used. Antibiotics of the Gram-positive and Gram-negative series were used as standard of reference of the microorganisms' susceptibility. The diluled oils were permeated at a paper disks, wich were placed on an agar previously sown surface. After incubation for $72 \mathrm{~h}$ at $30^{\circ} \mathrm{C}$, with observation at every $24 \mathrm{~h}$, the results obtained showed that the Brazilian clove essential oil affected a higher number of microorganisms, followed by Indian clove and peppermint. In relation to the microorganisms tested, the yeasts were the most resistant, while the Gram-positive bacteria were more sensitive to essential oils when compared to the Gram-negative. The concentrated oils showed higher effect than the diluted ones. In relation to the tested dilutions the $10 \%$ one was the most efficient, being observed that, as the concentration of essential oil increases, the inhibitory effect also increases. Some of the essential oils showed better performance than the antibiotics used as standard.

KEY-WORDS: ANTIMICROBIAL ACTIVITY; ESSENTIAL OILS.

\section{REFERÊNCIAS}

1 ARORA, D.S.; KAUR, J. Antimicrobial activity of spices. Internation Journal of Antimicrobials Agents, v.12, p.257-262, 1999.

2 AURELI, P.; CONSTANTINI, A.; ZOLEA, S. Antimicrobial activity of essential oils against Listeria monocytogenes. Journal of Food Protection, v. 55, p.344-348, 1992.

3 BEDIN, C.; GUTKOSKI, S. B.; WIEST, J. M. Atividade antimicrobiana das especiarias. Higiene Alimentar, V.13, p.26-29, 1999

4 BEUCHAT, L.R.; GOLDEN, D. A. Antimicrobials occurring naturally in foods. Food Technology, v.43, p.134142, 1989.

5 BOYLE, W. Spices and essential oils as preservatives. Am. Perfum. Essent. Oil, v.66, p.25-28, 1955.

6 BRANEN, A.L.; DAVIDSON, P.M.; KATZ, B. Antibacterial properties of phenolic antioxidants and lipids. Food Technololgy, v.34, p.51-53, 1980.

7 BRIOZZO, J.; NENEZ, L.; CHIRIFE, J.; HERSZAGE, L.; D'AQUINO, M. Antimicrobial activity of clove oil dispersed in a concentrated sugar solution. Journal of Applied Bacteriology, v.66, p.69-75, 1989.

8 BULLERMAN, L. B. Inhibition of aflatoxin production by cinnamon. Journal of Food Science, v.39, p.11631165,1974

9 COSENTINO, S.; TUBEROSO, C.I.G.; PISANO, B.; SATTA, M.; MASCIA, V.; ARZEDI, E.; PALMAS, F. In vitro antimicrobial activity and chemical composition of Thymus essential oils. Letters Applied Microbiology, v.29, p.130-135, 1999.

10 DEANS, S.G.: RITCHIE, G. Antibacterial properties of plant essential oils. Internation Journal of Food Microbiology, v.5, p.165-180, 1987.

11 DWIVIDI, S. A.; DUBEY, B. L. Potential use of essential oil of the trachyepermun ammy against seed borne fungi of guar (Cyamopsis tetragonoloba L.). Mycopathologia, v.121, p.101-104, 1993. 
12 ELGAYYAR, M.; DRAUGHON, F.A.; GOLDEN, D.A.; MOUNT, J. R. Antimicrobial activity of essential oils from plants against selected pathogenic and saprophytic microorganisms. Journal of Food Protection, v.64, p.10191024, 2001.

13 FARAG, R.; DAW, Z.; ABO-RAYA, S. Influence of some spice essential oils on A. parasiticus growth and production of aflatoxins in a synthetic medium. Journal of Food Science, v.54, p.74-76, 1989.

14 GONÇALVES, D. Química orgânica experimental. São Paulo: McGraw-Hill, 1990. p.60-64.

15 GOULD, G. W. Industry perspective on the use of natural antimicrobials and inhibitors for food applications. Jounal of Food Protection, v.45, p.82-85, 1995.

16 HOFFMANN, F.L.; SOUZA, S.J.F.; GARCIA-CRUZ, C.H.; VINTURIM, T.M.; DUTRA, A.L. Determinação da atividade antimicrobiana "in vitro" de quatro óleos essenciais de condimentos e especiarias. Boletim do CEPPA, v.17, p.11-20, 1999.

17 ISMAIEL, A.; PIERSON, M. D. Inhibition of growth and germination of Clostridium botulinum 33A, 40B and 1623E by essential oils of spices. Journal of Food Science, v.5, p.1676-1678, 1990.

18 KABARA, J.J. Fatty acids and derivatives as antimicrobial agents - a review. AOCS Monograph, v.5, p.1-14, 1979.

19 KOUTSOUMANIS, K.; LAMBROPOULOU, K.; NYCHAS, G-J.E. A predictive model for the non-thermal inactivation of Salmonella enteritidis in a food model system supplemented with a natural antimicrobial. International Journal of Food Microbiology, v.49, p.63-74, 1999.

20 KURYLOWICZ, W. Antibióticos: uma revisão crítica. Universidade Federal de Pernambuco, v.1, p.15-20, 1981.

21 KYUNG, K. H.; PARK, K. K.; KIM, Y. S. Isolation and caracterization of bacteria resistent to the antimicrobial activity of garlic. Journal of Food Science, v.61, p.226-229, 1996.

22 MARINO, M.; BERSANI, C.; COMI, G. Antimicrobial activity of the essential oils of Thymus vulgaris L. measured using a bioimpedometric method. Journal of Food Protection, v.62, p.1017-1023, 1999.

23 MAU, J.-L.; CHEN, C.-P.; HSIEH, P. C. Antimicrobial effects of extracts from Chinese chive, cinnamon and corn fructus. Journal of Agriculture and Food Chemistry, v.49, p.183-188, 2001.

24 MCKELLAR, R.C.; PAQUET, A.; MA, C.Y. Antimicrobial activity of fatty N-acylamino acids against gram-positive food borne pathogens. Internation Journal of Food Microbiology, v.9, p.67-76, 1992.

25 MONTES-BELMONT, R.; CARVAJALL, M. Control of Aspergillus flavus in maize with plant essential oils and their components. Journal of Food Protection, v.61, p.616-619, 1998.

26 MOROZUMI, S. Isolation, purification and antibiotic activity of o-methoxycinnamaaldyde from cinnamon. Applied Enviromental Microbiology, v.36, p.577-583, 1978.

27 NAKATANI, N. Antioxidative and antimicrobial constituents of herbs and spices. Devel. Food Sci., v.34, p.251271, 1994.

28 NYCHAS, G.J.E. Natural antimicrobials from plants. In: GOULD, G.W. (Ed.). New methods of food preservation. London: Blackie Academic and Professional, 1995. p. 58-89.

29 O'GARA, E.; HILL, D.J.; MASLIN, D. J. Activities of garlic oil, garlic powder, and their diallyl constituents against Helicobacter pylori. Appl. Environ. Microbiol, v.66, p.2269-2273, 2000.

30 PATKAR, K.; USHA, C.; SHETTY, H.; PATER, N.; LACEY, J. Effect of spice essential oils on growth and aflatoxin $B_{1}$ production by $A$. flavus. Letters in Applied Microbiology, v.17, p.49-51, 1993.

31 PIPER, P. W.; THOMPSN, S.; PANDAJAINT, R.; HOLYOAK, C.; EGNER, R.; MUHLBAUER, M.; COOTE, P.; KUCGLER, R. The Pdr12 ATP-binding cassete ABC required for the development of weak acid resistence in Sacharomyces cerevisae. EMBO Journal, v.17, 173-181, 1998.

32 RUSSEL, A. D. Mechanisms of bacterial resistance to no antibiotics: food additives and food pharmaceutical preservatives. Journal of Applied Bacteriology, v.71, p.191-201, 1991

33 SALMERANM J.; POZO, R. Effect of cinnamon (Cinnamomun zeylanicum) and clove (Eugenia caryophyllus) on growth and toxigenesis of $A$. flavus. Microbiologie Aliments and Nutrition, v.9, p.83-87, 1991.

34 SMITH-PALMER, A.; STEWART, J.; FYFE, L. Antimicrobial properties of plant essential oils and essences against important food borne pathogens. Letters Applied Microbiology, v.26, p.118-122, 1998. 
35 SOLIMAN, K.M.; BADEAA, R. I. Effect of oil extracted from some medicinal plants on different mycotoxigenic fungi. Food and Chemical Toxicology, v.40, p.1669-1675, 2002.

36 WIEST, J.M. Atividade antimicrobiana das especiarias. Higiene Alimentar, v.12, p.26-29, 1999. 